\title{
Delayed working memory consolidation during the attentional blink
}

\author{
EDWARD K. VOGEL and STEVEN J. LUCK \\ University of Iowa, Iowa City, Iowa
}

\begin{abstract}
After the detection of a target (T1) in a rapid stream of visual stimuli, there is a period of 400600 msec during which a subsequent target (T2) is missed. This impairment in performance has been labeled the attentional blink. Recent theories propose that the attentional blink reflects a bottleneck in working memory consolidation such that T2 cannot be consolidated until after T1 is consolidated, and $\mathrm{T} 2$ is therefore masked by subsequent stimuli if it is presented while $\mathrm{T} 1$ is being consolidated. In support of this explanation, Giesbrecht \& Di Lollo (1998) found that when T2 is the final item in the stimulus stream, no attentional blink is observed, because there are no subsequent stimuli that might mask T2. To provide a direct test of this explanation of the attentional blink, in the present study we used the P3 component of the event-related potential waveform to track the processing of T2. When T2 was followed by a masking item, we found that the P3 wave was completely suppressed during the attentional blink period, indicating that T2 was not consolidated in working memory. When T2 was the last item in the stimulus stream, however, we found that the P3 wave was delayed but not suppressed, indicating that T2 consolidation was not eliminated but simply delayed. These results are consistent with a fundamental limit on the consolidation of information in working memory.
\end{abstract}

The visual working memory system has two significant limitations. First, it has a storage capacity of only three to four items (Sperling, 1960; Vogel, Woodman, \& Luck, 2001). Second, the process that consolidates transient perceptual representations into durable working memory representations is slow and attention demanding (Jolicœur \& Dell'Acqua, 1998; Potter, 1976). This second limitation has received considerable study in the context of attentional blink experiments, in which a subject attempts to detect two targets embedded in a rapid stream of stimuli. When the second target (T2) is presented within a few hundred milliseconds after the first target (T1), the observer is frequently unable to report the identity or even the presence of T2 (Broadbent \& Broadbent, 1987; Reeves \& Sperling, 1986). This period of suppressed performance for $\mathrm{T} 2 \mathrm{oc}-$ curs only when subjects are instructed to attend to T1, and it is analogous to the impairment that would be triggered by a T1-triggered eyeblink; thus, it has been labeled the attentional blink (Raymond, Shapiro, \& Arnell, 1992).

Many studies have demonstrated that T2 is fully perceived during the attentional blink period even though it cannot be accurately reported (Jolicœur \& Dell'Acqua, 2000; Maki, Frigen, \& Paulson, 1997; Shapiro, Driver,

This study was supported by grants from the National Institute of Mental Health (MH56877), the National Science Foundation(SBR 9809126), and the Human Frontier Science Program (RG0136). We thank Ed Awh, Marvin Chun, Barry Giesbrecht, Pierre Jolicœur, and Geoff Woodman for very helpful discussions of the ideas presented in this article. Correspondence should be addressed to E. K. Vogel, Department of Psychology, 1227 University of Oregon, Eugene, OR 97403-1227 (email:vogel@darkwing.uoregon.edu).
Ward, \& Sorensen, 1997; Vogel, Luck, \& Shapiro, 1998), implying that the impaired performance arises at a postperceptual stage. Most explanations of the attentional blink have therefore focused on impairments in working memory in general and the process of working memory consolidation in particular (Chun \& Potter, 1995; Giesbrecht \& Di Lollo, 1998). These explanations propose that the rapid rate of stimulus presentation in this paradigm makes it necessary to protect the perceptual representations of $\mathrm{T} 1$ and $\mathrm{T} 2$ from being overwritten by subsequent stimuli. However, because this consolidation process is relatively slow, T1 may still be undergoing consolidation when T2 is presented, and $\mathrm{T} 2$ may therefore be overwritten by subsequent stimuli.

Giesbrecht and Di Lollo (1998) provided support for this explanation by demonstrating that the impairment in T2 accuracy during the attentional blink period is a consequence of visual masking. Using variants of the standard attentional blink paradigm, they compared two conditions, one in which T2 was followed by a single nontarget item (masked condition), and one in which $\mathrm{T} 2$ was the last item in the stream (unmasked condition). In the masked condition, they found a normal attentional blink pattern, with impaired accuracy when $\mathrm{T} 1$ preceded $\mathrm{T} 2$ by two to five items. However, in the unmasked condition, no attentional blink was observed. That is, accuracy was nearly perfect irrespective of the delay between $\mathrm{T} 1$ and $\mathrm{T} 2$. This was not merely a ceiling effect, because the same pattern was observed when $\mathrm{T} 2$ was presented with simultaneous masking noise that lowered performance away from ceiling. These results suggest that the attentional blink occurs because $\mathrm{T} 2$ is overwritten by the subsequent nontarget item, which in 
turn occurs because consolidation processes are being devoted to $\mathrm{T} 1$ and are unavailable for $\mathrm{T} 2$.

This interpretation implies that the perceptual representation of $\mathrm{T} 2$ can persist for a significant period of time if it is not followed by another stimulus (see Ross \& Jolicœur, 1999). That is, when T2 is the last item in the stream, its perceptual representation is still available when the consolidation of T1 has been completed. The perceptual representation of T2 is then transferred into working memory once the consolidation of $\mathrm{T} 1$ has been completed. Thus, when $\mathrm{T} 2$ is followed by additional items, it fails to be consolidated in working memory during the attentional blink period, but when $\mathrm{T} 2$ is the final item, there is merely a delay in the transfer of T2 into working memory. This delay is presumably short enough so that it does not lead to substantial decay of the $\mathrm{T} 2$ representation. In the present study, we tested this explanation by using event-related potentials (ERPs) to measure the time course of $\mathrm{T} 2$ processing.

The proposed delay in the transfer of $\mathrm{T} 2$ into working memory could potentially be measured with behavioral reaction time (RT) measures. For example, it seems plausible that the T2 RT would be slower during the typical attentional blink period. Indeed, Zuvic, Visser, and Di Lollo (2000) measured RTs to unmasked T2 items and found a significant slowing of RTs when the delay between the two targets was short, which suggests that consolidation processes were delayed. However, this approach requires an immediate speeded response to $\mathrm{T} 2$ and consequently increases the response selection load for T2. As a result, the RT delays may have been caused by delays in response selection rather than delays in working memory consolidation. ERP recordings, in contrast, make it possible to measure the time course of T2 processing without any special response requirements. Moreover, they can provide more direct information regarding the specific stage of processing that is delayed.

The present study focuses on the P3 wave, which is the third major positive ERP component and typically peaks around $400 \mathrm{msec}$ poststimulus for a visual target. The P3 wave is broadly distributed across most of the scalp, but it is usually maximal at central and parietal electrode sites. P3 amplitude is inversely related to the probability of a task-defined stimulus class. For example, if a subject is shown a series of pictures of animals containing $10 \%$ birds and $90 \%$ mammals and is asked to indicate whether each animal is a bird or a mammal, the birds will elicit a large P3 wave and the mammals will elicit a small P3 wave. From this sensitivity to the probability of task-defined stimulus categories, it can be inferred that the $\mathrm{P} 3$ wave must occur after the subject has classified the stimulus according to task-specific rules, and the P3 wave must therefore reflect a postperceptual process. Moreover, several studies have shown that the $\mathrm{P} 3$ reflects a process that precedes response selection (e.g., Kramer, Wickens, \& Donchin, 1983; Magliero, Bashore, Coles, \& Donchin, 1984).

On the basis of findings such as these, Donchin and Coles have proposed that the $\mathrm{P} 3$ wave reflects the updating of working memory (Donchin, 1981; Donchin \& Coles,
1988). We have previously found that the T2-elicited $\mathrm{P} 3$ wave was completely suppressed during the attentional blink period whereas earlier ERP components were not suppressed (Vogel et al., 1998), consistent with the proposal that the T2 item is perceived but not stored in working memory during the attentional blink period. In the present study, we include conditions in which $\mathrm{T} 2$ is the last item in the stimulus stream. If the consolidation model of the attentional blink is correct, and the consolidation of $\mathrm{T} 2$ is delayed when T2 is unmasked, the P3 component should not be suppressed in these conditions, but should merely be delayed.

Stimuli are presented at a rapid rate in the attentional blink paradigm, and the ERP response to one stimulus is therefore overlapped by the ERP responses elicited by the preceding and subsequent stimuli. To isolate the T2elicited P3 wave, we used a subtraction technique that takes advantage of the probability sensitivity of the P3 wave (for more details, see Vogel et al., 1998). Specifically, the T2 stimulus was either the letter $\mathrm{E}$ or a non-E letter, with $E$ presented on $25 \%$ of the trials and a non-E letter presented on $75 \%$ of the trials. Subjects reported whether T2 was an E or a non-E letter. Because the P3 wave should be much larger for the infrequent $\mathrm{E}$ stimuli than for the frequent non-E stimuli, it is possible to isolate the T2elicited P3 wave by subtracting non-E trials from E trials. This subtraction procedure eliminates any brain activity except the differential brain activity elicited when $\mathrm{T} 2$ is an $E$ versus a non-E, and the responses to the preceding and subsequent stimuli are therefore subtracted away.

\section{METHOD}

\section{Subjects}

Ten college students participated for course credit or monetary compensation. These subjects were 18-20 years old, reported normal or corrected-to-normal visual acuity, had normal color vision, and reported no history of neurological problems.

\section{Stimuli and Procedure}

The stimuli were presented on a computer monitor with a gray background $\left(6.7 \mathrm{~cd} / \mathrm{m}^{2}\right)$ at a distance of $70 \mathrm{~cm}$. As is illustrated in Figure 1, each trial consisted of a rapid serial stream of 19 letters and a single digit. Each character in the stream was presented individually at fixation for $33 \mathrm{msec}$, followed by a $50-\mathrm{msec}$ interstimulus interval. The characters were $0.8^{\circ}$ in height and varied proportionally in width. The nontargets were randomly selected uppercase letters (A-Z, with the exception of E), drawn in black $\left(2.6 \mathrm{~cd} / \mathrm{m}^{2}\right)$. $\mathrm{T} 1$ was a digit, also drawn in black. T2 was an uppercase letter, drawn in white $\left(17.1 \mathrm{~cd} / \mathrm{m}^{2}\right)$; this letter was the letter $\mathrm{E}$ on $25 \%$ of the trials and some other letter, selected at random, on $75 \%$ of the trials. At the end of each trial, the subjects pressed one of two buttons to indicate whether $\mathrm{T} 1$ was an even or odd number, and they pressed a third button if $\mathrm{T} 2$ was the letter E. These responses were unspeeded.

As is shown in Figure 1, T2 was always either the third or the seventh character following the T1 (denoted as lag 3 and lag 7), and either was the last item in the stream (unmasked) or was followed by a single distractor (masked). Because each sequence consisted of 20 stimuli, the sequential position of T1 was determined by the T1-T2 lag and by whether T2 was the final or the penultimate item in the sequence. For example, when T2 was the penultimate item and the 


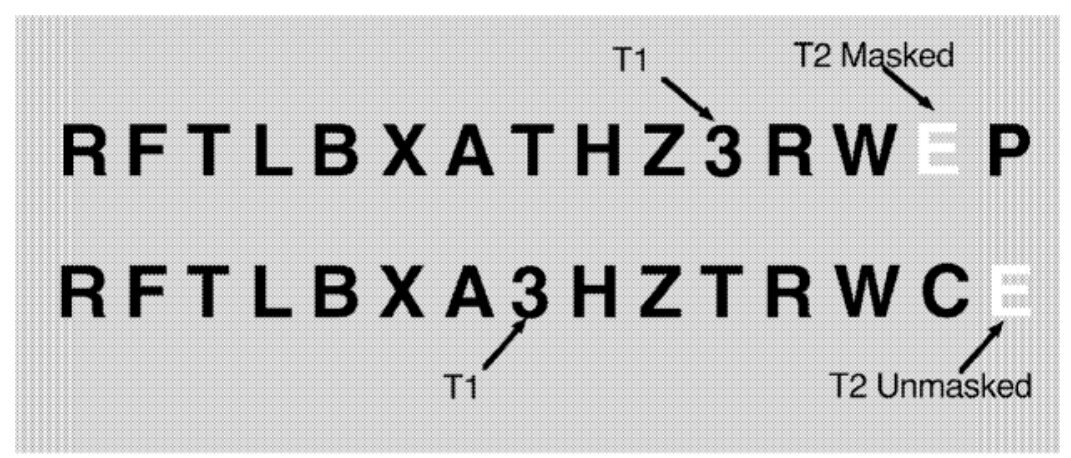

Figure 1. Sequences of stimuli presented serially at fixation. The upper row displays a lag 3 masked trial. The lower row displays a lag 7 unmasked trial.

T1-T2 lag was 7 items, T1 was the 12 th item in the stream. The subjects performed 140 trials of each combination of lag and mask conditions, distributed across six blocks.

\section{Recording and Analysis}

Electroencephalographic (EEG) and electrooculographic (EOG) recordings were made with our standard recording procedures (described in Vogel et al., 1998). Trials containing ocular artifacts (primarily eye blinks) were excluded from the averaged ERP waveforms. These artifacts led to the rejection of a mean of $11 \%$ of trials (the maximum rejection rate for an individual subject was $17 \%$ ). The averaged ERP waveforms were time locked to the onset of the T2 letter. Trials with incorrect T1 responses were excluded from the ERP waveforms and from all behavioral analyses.

The onset latency of the P3 was measured using the fractional area latency of the component, which was defined as the time point at which the waveform reached $25 \%$ of its area within the time window of 300-900 msec poststimulus (see Hansen \& Hillyard, 1984; similar results were obtained with traditional peak latency measures). P3 amplitude was measured as the mean amplitude of the waveform from 300 to $900 \mathrm{msec}$. All analyses were restricted to the central and parietal electrode sites, where the P3 wave is largest, but the same pattern was observed across the scalp.

\section{RESULTS}

\section{Behavior}

$\mathrm{T} 2$ accuracy for the masked and unmasked conditions is plotted as a function of lag in Figure 2. In the masked condition, performance was very poor at lag 3 but was substantially higher at lag 7. However, in the unmasked condition, performance was nearly perfect at both lags. We performed a two-factor analysis of variance (ANOVA) with masking condition (masked vs. unmasked) and lag (3 vs. 7) as repeated measures factors. This analysis yielded significant effects of both masking condition $[F(1,9)=255.38, p<.001]$ and $\operatorname{lag}[F(1,9)=139.32$, $p<.001]$, and a significant lag $\times$ masking interaction $[F(1,9)=246.65]$. Mean T1 accuracy was at $91.7 \%$, with no significant effect of either lag or masking condition (both $F_{\mathrm{S}}<1$ ). This pattern of results replicates Giesbrecht and Di Lollo's (1998) finding of a normal attentionalblink deficit for masked T2 items and no attentional blink when $\mathrm{T} 2$ is not followed by a mask. Note that, although the lack of an attentional blink in the unmasked condition could be a simple ceiling effect, Giesbrecht and Di Lollo demonstrated that the same pattern can be obtained when performance is not at ceiling.

\section{Electrophysiology}

The infrequent minus frequent difference waveforms are shown in Figure 3. At the central and parietal electrode sites, the waveforms primarily consisted of a large positive deflection beginning at approximately $350-400 \mathrm{msec}$ (the P3 component). In the masked condition, a significant P3 was elicited at lag 7, but the $\mathrm{P} 3$ was completely suppressed at lag 3 (mean amplitude of approximately $0 \mu \mathrm{V}$ ). This amplitude difference across the two lags was significant $[F(1,9)=24.3, p<.01]$. These results replicate Vogel et al.'s (1998) finding of a suppression of the P3 component for targets presented during the attentional blink.

In the unmasked condition, a substantial P3 component was elicited at both lag 3 and lag 7. P3 amplitude did not

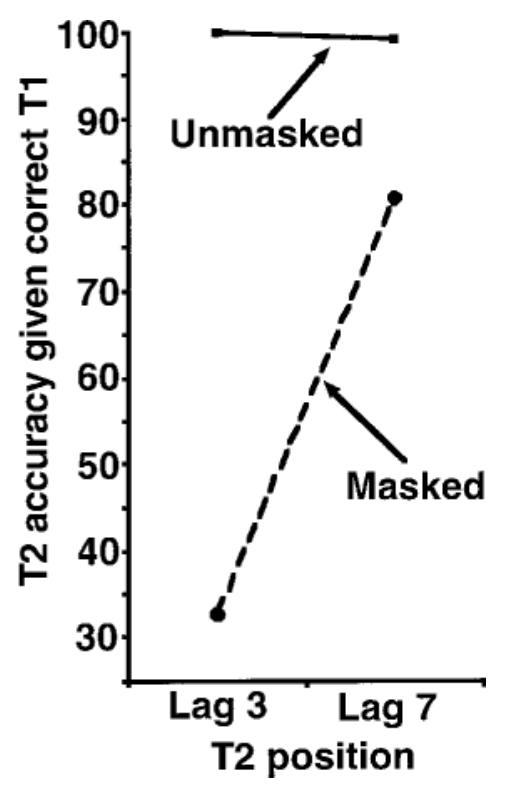

Figure 2. Accuracy for the second target (T2) as a function of lag for the masked and unmasked conditions. 


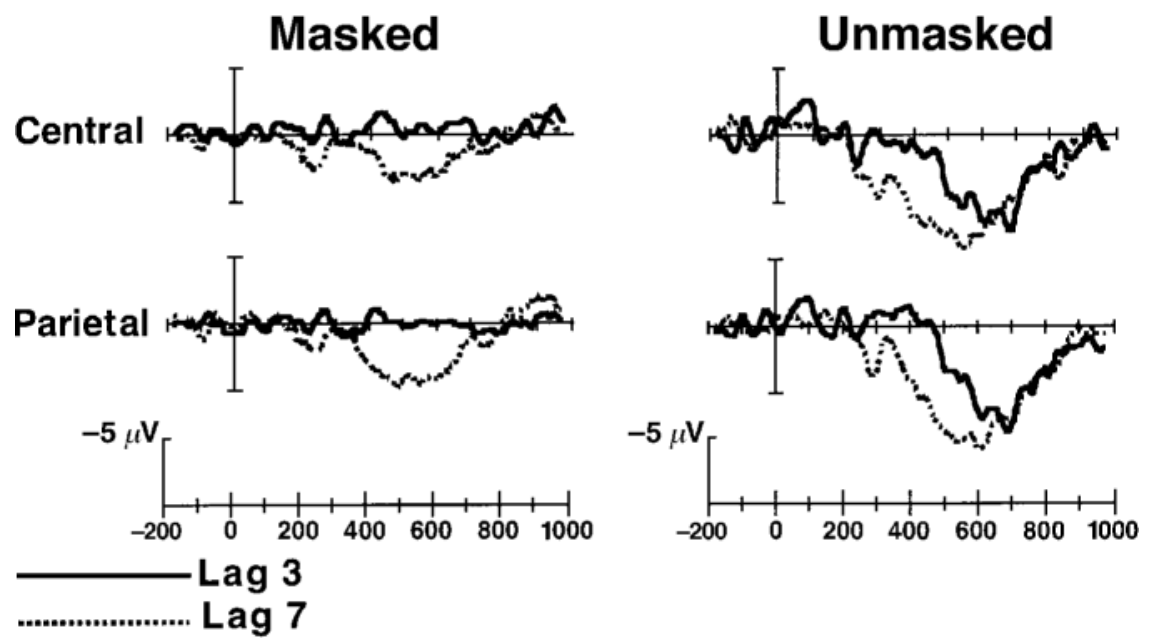

Figure 3. Grand average difference waveforms (infrequent T2 minus frequent T2) for two electrode sites $(\mathrm{Cz}$ and $\mathrm{Pz})$ for each of the conditions. Note that negative voltage is plotted upward.

differ significantly across the two lags $[F(1,9)=1.21, p>$ .25]. However, $\mathrm{P} 3$ onset latency was approximately $104 \mathrm{msec}$ later for lag 3 than for lag $7[F(1,9)=17.31, p<.01]$. As predicted by consolidation models, P3 onset latency was indeed substantially delayed for targets presented during the typical attentional blink period.

As in the study of Vogel et al. (1998), the probabilitysensitive $\mathrm{P} 2$ component (peak latency of about $250 \mathrm{msec}$ ) was suppressed during the attentional blink in both the masked and the unmasked conditions (both $p$ s $<.01$ ). Unfortunately, there is very little evidence regarding which cognitive process the $\mathrm{P} 2$ reflects, and it is therefore difficult to make even a tentative interpretation of this $\mathrm{P} 2$ suppression effect.

\section{DISCUSSION}

The primary goal of this study was to test the delayedconsolidation hypothesis by measuring the onset latency of the P3 component for unmasked T2 items presented either during or after the typical attentional blink period. When T2 was followed by a mask, we found evidence of a large attentional blink, with substantial suppression of both accuracy and P3 amplitude at lag 3 relative to lag 7 . When $\mathrm{T} 2$ was not followed by a mask, we found no behavioral evidence of the attentional blink, with equally high accuracy for both lags. However, when an unmasked T2 was presented at lag 3, the onset latency of the P3 was delayed by over $100 \mathrm{msec}$ relative to lag 7 . That is, despite the absence of a behavioral attentionalblink for unmasked targets, P3 latency was delayed during the typical attentional blink period.

The results of our four conditions closely match the predictions made by consolidation models of the attentional blink (Chun \& Potter, 1995; Jolicœur, 1999; Jolicœur \& Dell' Acqua, 1998). When T2 is masked at short lags, the mod- els predict that $\mathrm{T} 2$ should be overwritten by a subsequent stimulus prior to being consolidated, which is consistent with our finding of a complete suppression of the P3 during the attentional blink. When T2 follows shortly after $\mathrm{T} 1$ but is not masked, consolidation of T2 is again postponed, and this is reflected by the delayed onset of the P3 wave. However, the absence of a mask allows the T2 representation to remain sufficiently active to be consolidated after T1 processing is complete, leading to accurate behavioral responses. Thus, the pattern of $\mathrm{P} 3$ amplitude and latency effects observed here fits perfectly with the predictions of consolidation models of the attentional blink.

Some investigators have argued against the proposal that the P3 wave reflects the updating of working memory (e.g., Verleger, 1988), but the conclusions of the present study are not tied to this specific hypothesis. The procedures used here guarantee that the P3 activity shown in Figure 3 reflects processing that follows the task-defined categorization of the stimulus, and other studies have shown that the $\mathrm{P} 3$ wave reflects processes that precede response selection (e.g., McCarthy \& Donchin, 1983). Thus, we can conclude with confidence that the present results indicate that central processes within a relatively narrow range are postponed during the attentional blink. When coupled with the finding that masking of T2 is crucial for producing an attentional blink (Giesbrecht \& Di Lollo, 1998), working memory consolidation seems to be the best candidate for the delayed process.

In addition to providing evidence in support of consolidation models of the attentional blink, the present study also supports a distinction between the mechanisms underlying the psychological refractory period (PRP) and the attentional blink. The PRP is a well-studied behavioral phenomenon observed when a subject must make speeded responses to each of two unmasked targets (again called $\mathrm{T} 1$ and $\mathrm{T} 2$ ). Responses to $\mathrm{T} 2$ are slowed when $\mathrm{T} 2$ is pre- 
sented within a few hundred milliseconds after T1, and this bears a close resemblance to the attentional blink paradigm. However, whereas most models of the attentional blink have focused on limitations in working memory consolidation, models of the PRP have indicated that limitations on later processing stages such as response selection (De Jong, 1993; Johnston, McCann, \& Remington, 1996; Pashler, 1989) or strategic task scheduling (Meyer \& Kieras, 1997; Schumacher et al., 2001) could be the cause of this dual-task slowing. In a recent study of the locus of the PRP, Luck (1998) found that P3 latency was not substantially delayed during the PRP, despite a substantial slowing of response times. These results indicated that the processing delay during the PRP occurs sometime after the target reaches working memory, which is consistent with postmemory consolidation models of the PRP. Therefore, the present finding of a delayed P3 during the attentional blink provides a clear temporal distinction between the consolidation process and the later response/ strategy-related processes that underlie the PRP effect. Presently, there is substantial evidence that these two mechanisms of attention utilize the same underlying central resources (Jolicœur, 1999). However, the present results suggest that although they may draw from similar resources, the attentional blink and PRP reflect interference at temporally distinct processing stages.

\section{REFERENCES}

Broadbent, D. E., \& Broadbent, M. H. P. (1987). From detection to identification: Response to multiple targets in rapid serial visual presentation. Perception \& Psychophysics, 42, 105-113.

Chun, M. M., \& Potter, M. C. (1995). A two-stage model for multiple target detection in rapid serial visual presentation. Journal of Experimental Psychology: Human Perception \& Performance, 21, 109-127.

De Jong, R. (1993). Multiple bottlenecks in overlapping task performance. Journal of Experimental Psychology: Human Perception \& Performance, 19, 965-980.

Donchin, E. (1981). Surprise! . . Surprise? Psychophysiology, 18, 493513.

Donchin, E., \& Coles, M. G. H. (1988). Is the P300 component a manifestation of context updating? Behavioral \& Brain Sciences, 11, 357374.

Giesbrecht, B. L., \& Di Lollo, V. (1998). Beyond the attentional blink: Visual masking by object substitution. Journal of Experimental Psychology: Human Perception \& Performance, 24, 1454-1466.

Hansen, J. C., \& Hillyard, S. A. (1984). Effects of stimulation rate and attribute cuing on event-related potentials during selective auditory attention. Psychophysiology, 21, 394-405.

Johnston, J. C., McCann, R. S., \& Remington, R. W. (1996). Selective attention operates at two processing loci. In A. H. Kramer, M. G. H. Coles, \& G. D. Logan (Eds.), Converging operations in the study of visual selective attention (pp. 439-458). Washington, DC: American Psychological Association.

JoLICCEUR, P. (1999). Concurrent response-selection demands modulate attentional blink. Journal of Experimental Psychology: Human Perception \& Performance, 25, 1097-1113.

Joliceur, P., \& Dell'Acqua, R. (1998). The demonstration of shortterm consolidation. Cognitive Psychology, 36, 138-202.
Jolicceur, P., \& Dell'Acqua, R. (2000). Selective influence of second target exposure duration and Task ${ }_{1}$ load effects in the attentional blink phenomenon. Psychonomic Bulletin \& Review, 7, 472-479.

Kramer, A. F., Wickens, C. D., \& Donchin, E. (1983). An analysis of the processing requirements of a complex perceptual-motor task. Human Factors, 25, 597-621.

LUCK, S. J. (1998). Sources of dual-task interference: Evidence from human electrophysiology. Psychological Science, 9, 223-227.

Magliero, A., Bashore, T. R, Coles, M. G. H., \& Donchin, E. (1984). On the dependence of $\mathrm{P} 300$ latency on stimulus evaluation processes. Psychophysiology, 21, 171-186.

Maki, W. S., Frigen, K., \& Paulson, K. (1997). Associative priming by targets and distractors during rapid serial visual presentation: Does word meaning survive the attentional blink? Journal of Experimental Psychology: Human Perception \& Performance, 23, 1014-1034.

McCarthy, G., \& Donchin, E. (1983). Chronometric analysis of human information processing. In A. W. K. Gaillard \& W. Ritter (Eds.), Tutorials in ERP research: Endogenous components (pp. 251268). Amsterdam: North-Holland.

Meyer, D. E., \& Kieras, D. E. (1997). A computational theory of executive cognitive processes and multiple-task performance: Part 2. Accounts of the psychological refractory period phenomena. Psychological Review, 104, 3-65.

PAshler, H. (1989). Dissociations and dependencies between speed and accuracy: Evidence for a two-component theory of divided attention in simple tasks. Cognitive Psychology, 21, 469-514.

Potter, M. C. (1976). Short-term conceptual memory for pictures. Journal of Experimental Psychology: Human Learning \& Memory, 2 , 509-522.

Raymond, J. E., Shapiro, K. L., \& Arnell, K. M. (1992). Temporary suppression of visual processing in an RSVP task: An attentional blink? Journal of Experimental Psychology: Human Perception \& Performance, 18, 849-860.

Reeves, A., \& Sperling, G. (1986). Attention gating in short-term visual memory. Psychological Review, 93, 180-206.

Ross, N. E., \& Jolicceur, P. (1999). Attentional blink for color. Journal of Experimental Psychology: Human Perception \& Performance, 25, 1483-1494.

Schumacher, E. H., Seymour, T. L., Glass, J. M., Fencsik, D. E., Lauber, E. J., Kieras, D. E., \& Meyer, D. E. (2001). Virtually perfect time sharing in dual-task performance: Uncorking the central bottleneck. Psychological Science, 12, 101-108.

Shapiro, K., Driver, J., Ward, R, \& Sorensen, R. E. (1997). Priming from the attentional blink: A failure to extract visual tokens but not visual types. Psychological Science, 8, 95-100.

SperLing, G. (1960). The information available in brief visual presentations. Psychological Monographs, 74 (11, Whole No. 498), 29.

VERLEGER, R. (1988). Event-related potentials and cognition: A critique of the context updating hypothesis and an alternative interpretation of P3. Behavioral \& Brain Sciences, 11, 343-427.

Vogel, E. K., Luck, S. J., \& Shapiro, K. L. (1998). Electrophysiological evidence for a postperceptual locus of suppression during the attentional blink. Journal of Experimental Psychology: Human Perception \& Performance, 24, 1656-1674.

Vogel, E. K., Woodman, G. F., \& Luck, S. J. (2001). Storage of features, conjunctions, and objects in visual working memory. Journal of Experimental Psychology: Human Perception and Performance, 27, 92114.

Zuvic, S. M., Visser, T. A. W., \& Di Lollo, V. (2000). Direct estimates of processing delays in the attentional blink. Psychological Research, 63, 192-198.

(Manuscript received January 2, 2001; revision accepted for publication December 15, 2001.) 